This article was downloaded by: [National Taiwan University]

On: 14 April 2009

Access details: Access Details: [subscription number 908033515]

Publisher Taylor \& Francis

Informa Ltd Registered in England and Wales Registered Number: 1072954 Registered office: Mortimer House, 37-41 Mortimer Street, London W1T 3JH, UK

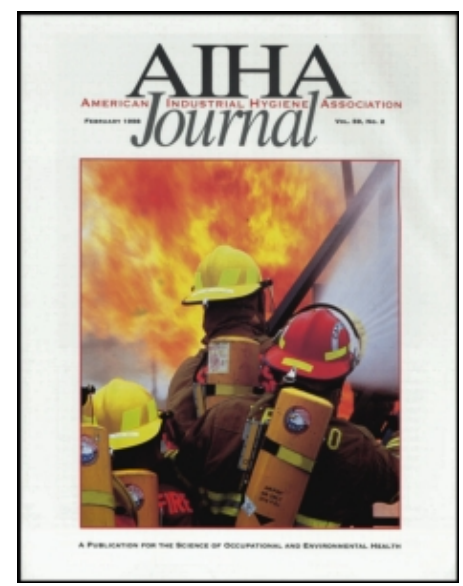

American Industrial Hygiene Association Journal

Publication details, including instructions for authors and subscription information:

http://www.informaworld.com/smpp/title content=t713608243

\title{
The Effects of Particle Charge on the Performance of a Filtering Facepiece
}

Chih-Chieh Chen a; Sheng-Hsiu Huang a

${ }^{a}$ Institute of Occupational Medicine and Industrial Hygiene, College of Public Health, National Taiwan University, 1 Jen-Ai Road, Sec. 1, Taipei, Taiwan.

Online Publication Date: 01 April 1998

To cite this Article Chen, Chih-Chieh and Huang, Sheng-Hsiu(1998)'The Effects of Particle Charge on the Performance of a Filtering Facepiece',American Industrial Hygiene Association Journal,59:4,227 - 233

To link to this Article: DOI: $10.1080 / 15428119891010488$

URL: http://dx.doi.org/10.1080/15428119891010488

\section{PLEASE SCROLL DOWN FOR ARTICLE}

\footnotetext{
Full terms and conditions of use: http://www.informaworld.com/terms-and-conditions-of-access.pdf

This article may be used for research, teaching and private study purposes. Any substantial or systematic reproduction, re-distribution, re-selling, loan or sub-licensing, systematic supply or distribution in any form to anyone is expressly forbidden.

The publisher does not give any warranty express or implied or make any representation that the contents will be complete or accurate or up to date. The accuracy of any instructions, formulae and drug doses should be independently verified with primary sources. The publisher shall not be liable for any loss, actions, claims, proceedings, demand or costs or damages whatsoever or howsoever caused arising directly or indirectly in connection with or arising out of the use of this material.
} 


\section{AUtHoRs \\ Chih-Chieh Chen Sheng-Hsiu Huang}

Institute of Occupational Medicine and Industrial Hygiene, College of Public Health, National Taiwan University, l Jen-Ai Road, Sec. 1, Taipei, Taiwan
The authors appreciate the financial support of the National Science Council of Taiwan through grant no. NSC83-0421-B-002001Z. S.H. Huang was supported by a stipend for graduate education awarded by the National Taiwan University during part of his MS study.

\section{The Effects of Particle Charge on the Performance of a Filtering Facepiece}

This study quantitatively determined the effect of electrostatic charge on the performance of an electret filtering facepiece. Monodisperse challenge corn oil aerosols with uniform charges were generated using a modified vibrating orifice monodisperse aerosol generator. The aerosol size distributions and concentrations upstream and downstream of an electret filter were measured using an aerodynamic particle sizer, an Aerosizer, and a scanning mobility particle sizer. The aerosol charge was measured by using an aerosol electrometer. The tested electret filter had a packing density of about 0.08 , fiber size of $3 \mu \mathrm{m}$, and thickness of $0.75 \mathrm{~mm}$. As expected, the primary filtration mechanisms for the micrometer-sized particles are interception and impaction, especially at high face velocities, while electrostatic attraction and diffusion are the filtration mechanisms for submicrometer-sized aerosol particles. The fiber charge density was estimated to be $1.35 \times 10^{-5}$ coulomb per square meter. After treatment with isopropanol, most of fiber charges were removed, causing the $0.3-\mu \mathrm{m}$ aerosol penetration to increase from 36 to $68 \%$. The air resistance of the filter increased slightly after immersion in the isopropanol, probably due to the coating of impurities in isopropanol. The aerosol penetration decreased with increasing aerosol charge. The most penetrating aerosol size became larger as the aerosol charge increased, e.g., from 0.32 to $1.3 \mu \mathrm{m}$ when the aerosol charge increased from 0 to 500 elementary charges.

Keywords: air-purifying devices, electret filter, filtering facepieces, particle charge, respirators

A ir-purifying devices are commonly used in the workplace for protection from both nuisance and hazardous materials. Among them, the filtering facepiece, also referred to as a disposable respirator, is the most popular with workers for many reasons: lighter burden, less visual obstruction, and low maintenance when compared with elastomeric respirators. Most filtering facepieces used today are made of electret material (material with significant electrical charges on the fibers). To quantitatively determine the fiber charge is a difficult and tedious process. However, the amount of charge on the fiber is one of the most critical factors influencing the performance and the quality of the facepiece, since the filter quality can be significantly improved with the addition of electrostatic removal force.
The effects of aerosol charge and relative humidity $(\mathrm{RH})$ on the filter efficiency of particulate air purifying respirators have been shown to be significant. The drop in filter efficiency was found to be approximately $10-20 \%$ between the charged and neutralized aerosol. The drop in efficiency due to $\mathrm{RH}$ pretreatment was $2-6 \%$. These studies concluded that the charge on the aerosol is more important than the degradation of the filter media from $\mathrm{RH}$ pretreatment. ${ }^{(1,2)}$ The variability in filter quality among the filtering facepieces of different manufacturers was found to be high. ${ }^{(3)}$ A recent study indicated that fiber charge is responsible for this difference. ${ }^{(4)}$ The study calculated the electrical charge on the filters by matching the single fiber efficiency calculation for mechanical and electrical removal with the experimental data for the chemically untreated filter. Filtering facepieces 
with high fiber charge densities provide greater protection than filtering facepieces made of mechanical fibers.

As to the aerosol charge in the workplace, it has been demonstrated that most aerosols were on average neutrally charged, and the charge carried by one particle rarely exceeded 50 elementary charges, and even moderately charged, the aerosols pose no problem to aerosol sampling. ${ }^{(5)}$ Although no clear evidence has ever been obtained that charged aerosols represent increased aerosol sampling bias and actual health hazards, ${ }^{(6)}$ the amount of charge carried by the particles is known to enhance the collection efficiency in filter tests. Consequently, the certification of air-purifying respirators under the National Institute for Occupational Safety and Health respirator standards requires that the challenge aerosol particles of sodium chloride and/or dioctyl phthalate be neutralized to create a worst case challenge aerosol.(7) To respond to this new requirement, the manufacturer has upgraded the filter tester (without aerosol neutralizer) by adding a discharger or a radioactive source. The filter tester is not equipped with an aerosol charge monitor, so there is no warranty that the charge balance is achieved or maintained when the neutralizer is contaminated or loses the polarity balance.

With electret facepieces becoming more popular, the increase in filtration efficiency due to the electrical force will become more significant because adding the charge to the fiber is one of the most efficient ways to enhance the filter quality. The electrostatic attraction will be even greater if the charge state of the challenge aerosols deviates from the Boltzmann charge equilibrium. Consequently, it is essential to understand further and determine quantitatively the influences of particle charge in electret and nonelectret filtering.

\section{EXPERIMENTAL MATERIALS AND METHODS}

$T^{-1}$ hree aerosol generation systems were used to produce aerosol particles with different size distributions, as shown in Figure 1. A constant output atomizer (model 3076, TSI Inc., St. Paul, Minn.) and an ultrasonic atomizing nozzle (model 8700-60, Sonotek Inc., Highland, N.Y.) were used to generate polydisperse submicrometer-sized and micrometer-sized aerosol particles, respectively. Corn oil was used as the test material. The output of the generator was then passed through a $10-\mathrm{mCi} \mathrm{Kr}-85$ radioactive source (model 3077, TSI Inc.) to neutralize the aerosol particles to the Boltzmann charge equilibrium.

A vibrating orifice monodisperse aerosol generator (VOMAG; model 3050, TSI, Inc.) was modified to generate monodisperse aerosol with uniform charge ${ }^{(8)}$ i.e., the charge on aerosol particles was controlled to uniform magnitude and polarity. A small amount of nitric acid was added to the corn oil-isopropanol solution to increase the conductivity, so that the control of the aerosol charge could be achieved. Due to the unavoidable presence of impurities in the solution, the lower size limit of the produced monodisperse aerosol particles was found to be about $0.8 \mu \mathrm{m}$.

Three different spectrometers were used to measure the aerosol concentration and size distribution: a scanning mobility particle sizer (SMPS; model 3934U, TSI Inc.) for particles smaller than $0.6 \mu \mathrm{m}$, an Aerosizer (Amherst Process Instruments Inc., Hadley, Mass.) for particles larger than $0.6 \mu \mathrm{m}$, and an aerodynamic particle sizer (APS; model 3310A, TSI Inc.) for particles larger than $0.8 \mu \mathrm{m}$. The APS was also used to verify the data provided by the Aerosizer and was found to give number concentrations close to the absolute concentration, which could also be derived from the dilution airflow and the generation frequency applied to the VOMAG. The total aerosol

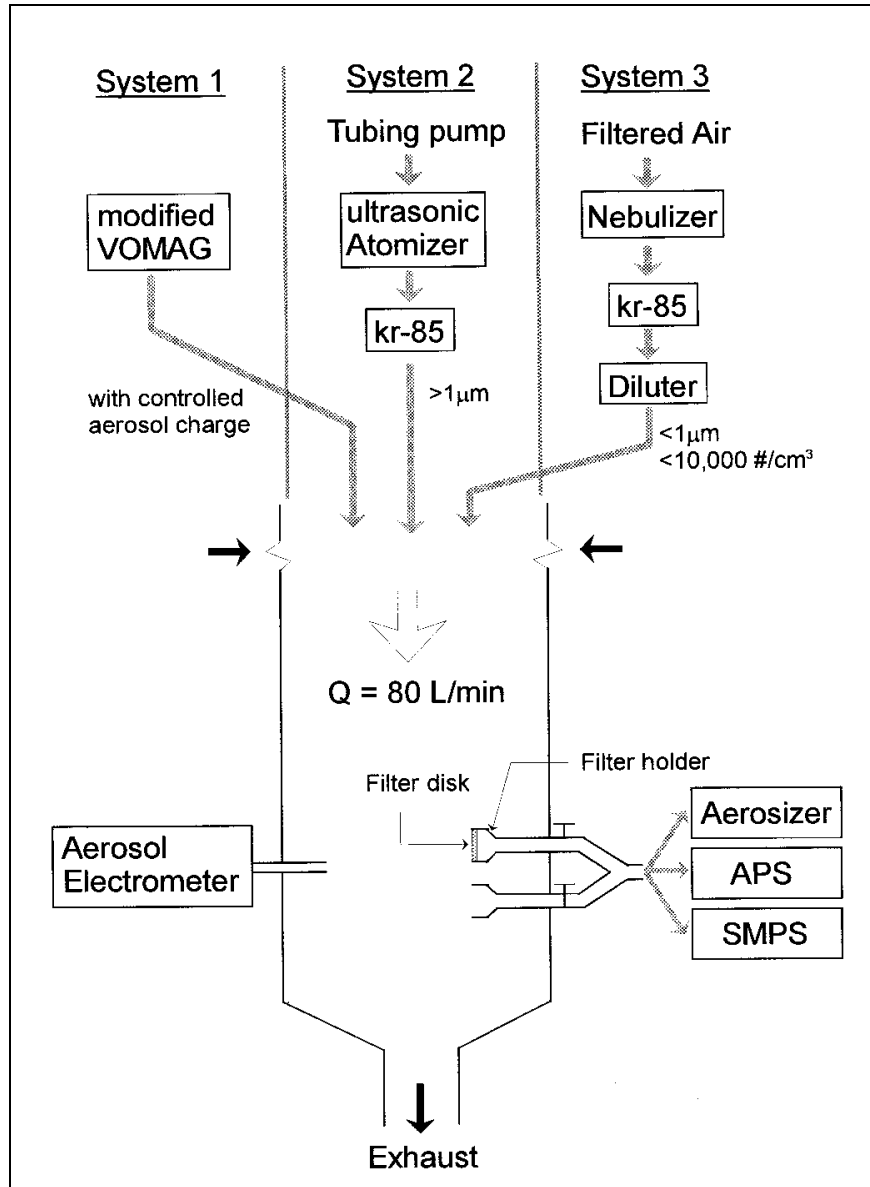

FIGURE 1. Schematic diagram of experimental setup

charge was measured using an aerosol electrometer (model 3068, TSI, Inc.). The charge per particle was then calculated using the particle number concentration measured by the APS.

Both of these instruments are real-time optical size-spectrometers, but they size aerosol by different principles and work in different size ranges. The Aerosizer, with a working size range from 0.2 to $700 \mu \mathrm{m}$ as claimed by the manufacturer, was designed to measure the aerodynamic size of the tested aerosol particles. The SMPS is capable of detecting particulate sizes ranging from 5 to $1000 \mathrm{~nm}$ by measuring the electrical mobility of the tested aerosol particles. To eliminate the uncertainty caused by the low sensitivity of Aerosizer when measuring particles smaller than $0.5 \mu \mathrm{m}$, and the deposition loss (for particles larger than $0.8 \mu \mathrm{m}$ ) due to the insertion of the impactor in the sampling train of the SMPS, the dividing particulate size of these two instruments was set at about $0.6 \mu \mathrm{m}$.

Aluminum foil was glued to the inner surface of the chamber and grounded to prevent aerosol deposition loss due to coulomb force. To reduce the coincidence effect of SMPS, the particle number concentration produced by the nebulizer was diluted to less than 10,000 particle $/ \mathrm{cm}^{3}$. Aerosol penetration and air resistance through a Pl class filtering facepiece was performed. The electret material was made of polypropylene. The filter properties of the tested masks were (as provided by the manufacturer): packing density of about 0.08 , thickness of $0.75 \mathrm{~mm}$, and fiber diameter of 3.0 $\mu \mathrm{m}$. The sampling flow rates through the filter holder were adjusted to the corresponding face velocities of $1,3,6$, and $10 \mathrm{~cm} / \mathrm{sec}$. All 
the airflows were controlled and monitored by mass flow controllers (Hastings Instruments, Hampton, Va.).

Test aerosol particles were sampled through a Y-shaped branched sampling train (shown in Figure 1) that allowed switching between the filtered line and an identical open line. Each line terminated with a filter holder, which was used to hold a filter disk (47 $\mathrm{mm}$ diameter) cut from the filtering facepiece consisting of electrically enhanced filter material. The filter disks were dipped in isopropanol for about 5 minutes and then dried naturally. This process has been shown in previous studies to remove the fiber charge. ${ }^{(4)}$ Five electret and 5 nonelectret filter disks (cut from 10 masks) were tested to examine the variability of the filter quality.

The experimental penetrations were then compared with the theoretical predictions. The theoretical aerosol penetration of a particle with $n$ elementary charges, $P_{n}$, through a filter is expressed in terms of total single fiber efficiency, $E_{\Sigma, n},{ }^{(9)}$

$$
P_{n}=\exp \left[\frac{-4 \alpha x E_{\Sigma, n}}{\pi d_{f}(1-\alpha)}\right]
$$

where $\alpha$ is the packing density, $x$ is the filter thickness, and $d_{f}$ is the fiber diameter. $E_{\Sigma, n}$ represents the combined effect of several individual single fiber filtration mechanisms and is given by:(10)

$$
\begin{aligned}
\mathrm{E}_{\mathrm{z}, \mathrm{n}}= & 1-\left(1-\mathrm{E}_{\mathrm{d}}\right)\left(1-\mathrm{E}_{\mathrm{r}}\right)\left(1-\mathrm{E}_{\mathrm{i}}\right)\left(1-\mathrm{E}_{\mathrm{g}}\right)\left(1-\mathrm{E}_{\mathrm{p}}\right) \\
& \times\left(1-\mathrm{E}_{\mathrm{c}, \mathrm{n}}\right)\left(1-\mathrm{E}_{\mathrm{m}, \mathrm{n}}\right)
\end{aligned}
$$

where $\mathrm{E}_{\mathrm{d}}$ is due to diffusion ${ }^{(11)}$

$\mathrm{E}_{\mathrm{r}}$ is due to interception ${ }^{(11)}$

$\mathrm{E}_{\mathrm{i}}$ is due to impaction ${ }^{(9)}$

$\mathrm{E}_{\mathrm{g}}$ is due to gravitational settling ${ }^{(9)}$

$\mathrm{E}_{\mathrm{p}}$ is due to dielectrophoretic force ${ }^{(12,13)}$

$\mathrm{E}_{\mathrm{c}, \mathrm{n}}$ is due to coulombic force ${ }^{(12,13)}$

$\mathrm{E}_{\mathrm{m}, \mathrm{n}}$ is due to image force. ${ }^{(14)}$

Equation 2 is an approximation based on the assumption that all mechanisms are independent. To identify the effects of interaction terms among the seven individual mechanisms is too complicated and not within the scope of this paper. The effects are smoothed out using the "equivalent fiber diameter," as will be discussed later.

The dominant filtration mechanisms for the submicrometersized particles are diffusional deposition and electrostatic attraction, which increase with decreasing face velocity because of the shorter retention time (within the filter) for aerosol particles and fibers to interact. Interception becomes significant as the ratio (particle diameter/fiber diameter) increases, and it is the only mechanism independent of face velocity. Inertial impaction of a particle on a fiber occurs because of the deviation of the particle from the streamline due to its own inertia. Inertial impaction is the only deposition mechanism that increases with increasing face velocity. Gravitational settling is generally small compared with other filtration mechanisms, and normally ignored in the modeling, except when aerosol size is extremely large and/or face velocity is unusually slow, which are not common when the filter is used for personal respiratory protection. The assumption that all fibers in a filter are treated as identical may be inexact and unfeasible for the real filters, but it does lead to a usable average and is used in this article.

\section{RESULTS AND DISCUSSION}

$\mathrm{T}$ he average pressure drop (of five) across the filter treated with isopropanol was found to be slightly higher than for the untreated filter (shown in Figure 2), although the difference is not

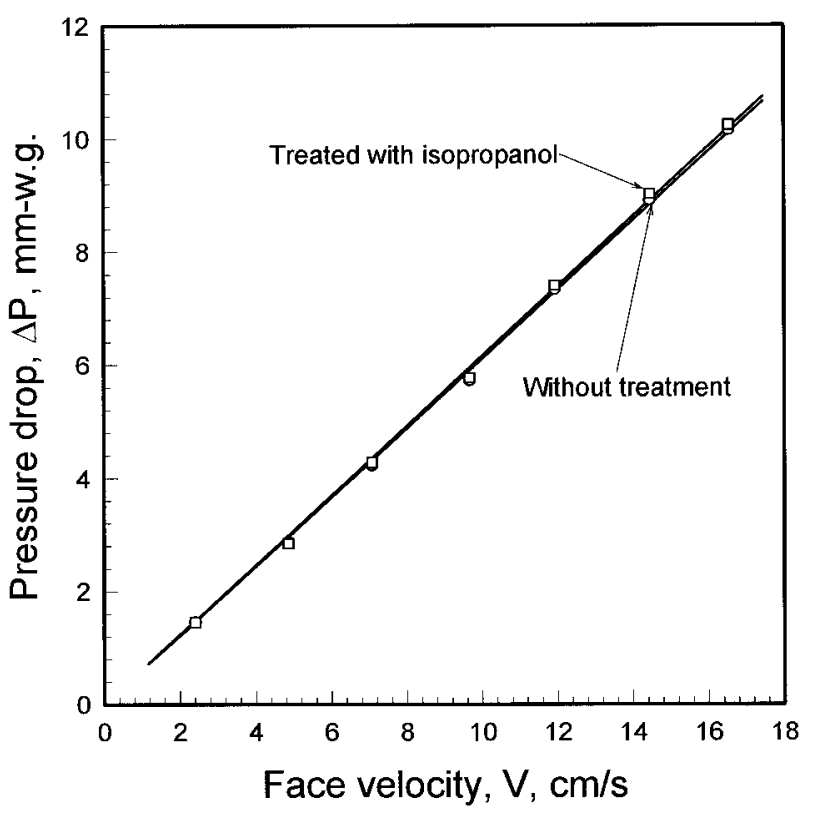

FIGURE 2. Effect of face velocity on the pressure drop across the filtering facepieces

statistically significant. The pressure drop increased linearly with increasing face velocity, indicating that the airflow through the filter medium was laminar. The small increase in the air resistance was probably caused by impurities in the isopropanol deposited on the fiber surface, which slightly increased the packing density. It is also possible that the increase in air resistance is due to a change of structure, possibly as a result of minor compression. The scanning electron micrographs, as shown in Figure 3, revealed no observable difference between the electret filter and the filter treated with isopropanol.

However, aerosol penetration through the filter treated with isopropanol was much higher than through the electret filter, as shown in Figure 4, which is composed of the data from two particle counters, the Aerosizer, and the SMPS. Figure 4 also shows that when tested at the face velocity of $10 \mathrm{~cm} / \mathrm{sec}$, the penetrations of $0.3-\mu \mathrm{m}$ aerosol through the treated filter and the electret filter were $70 \%$ and $34 \%$, respectively, indicating that the electrostatic force on the electret filter was diminished by the isopropanol. The penetrations of submicrometer-sized aerosol particles clearly increased with increasing face velocity, indicating that this filtering facepiece removed small particles by diffusion and/or electrostatic attraction. The most penetrating aerosol size through the treated filter decreased with increasing face velocity. This phenomenon was not as clear for the electret filter. If the data is presented in terms of collection efficiency instead of penetration percentage, the collection efficiency of $0.3-\mu \mathrm{m}$ aerosol by the treated filter was about $30 \%(=1-70 \%$ penetration, velocity 10 $\mathrm{cm} / \mathrm{sec}$ ). In addition to this $30 \%$ collection efficiency due to mechanical force, the electrical force of the electret filter added another $36 \%$, so that the aerosol penetration through the electret filter appeared to be $34 \%$, as shown in Figure 4 . Yet, a previous study ${ }^{(4)}$ reported that although isopropanol appeared to reduce the electrostatic force of the electret filter, there might still be a small amount of residual charges left on the fibers. 

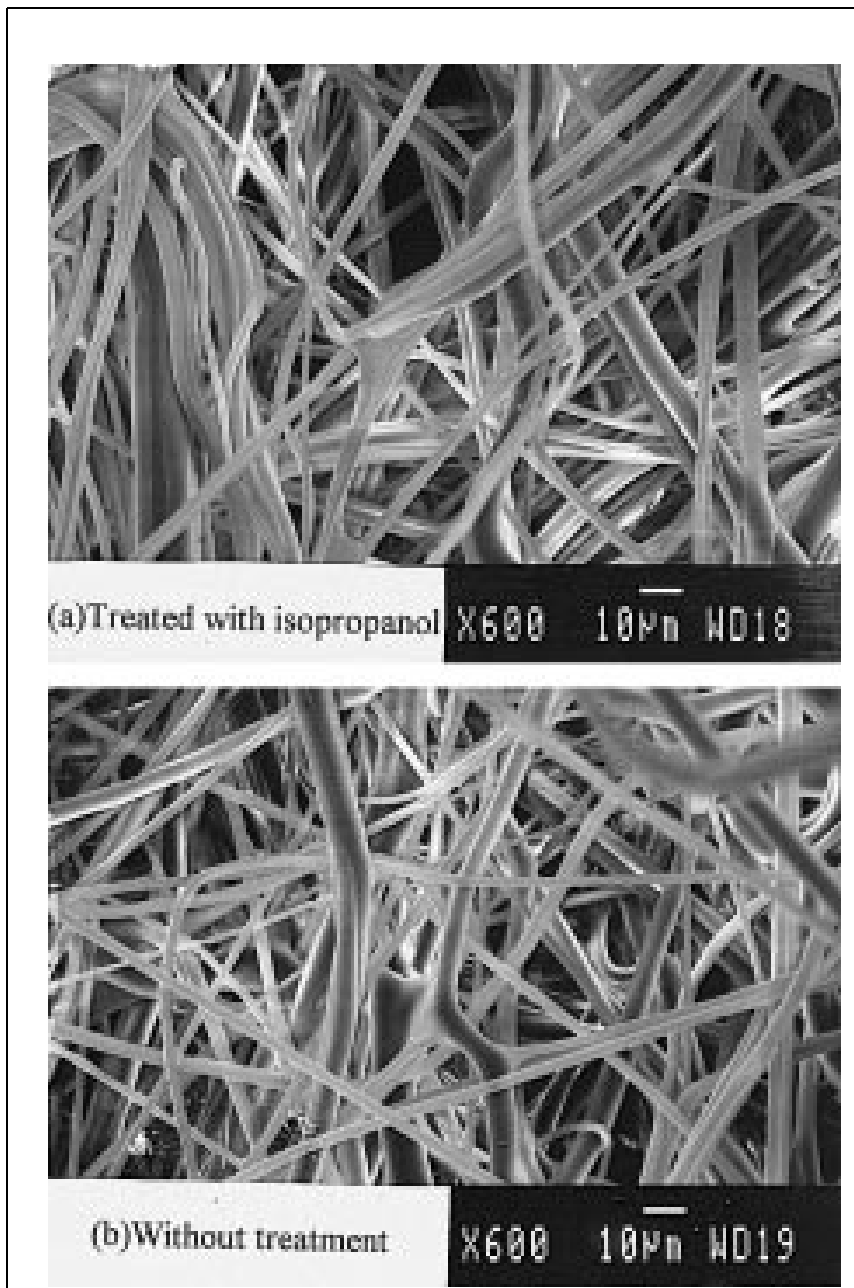

FIGURE 3. Scanning electron micrographs of filter media, (a) without treatment, and (b) treated with isopropanol

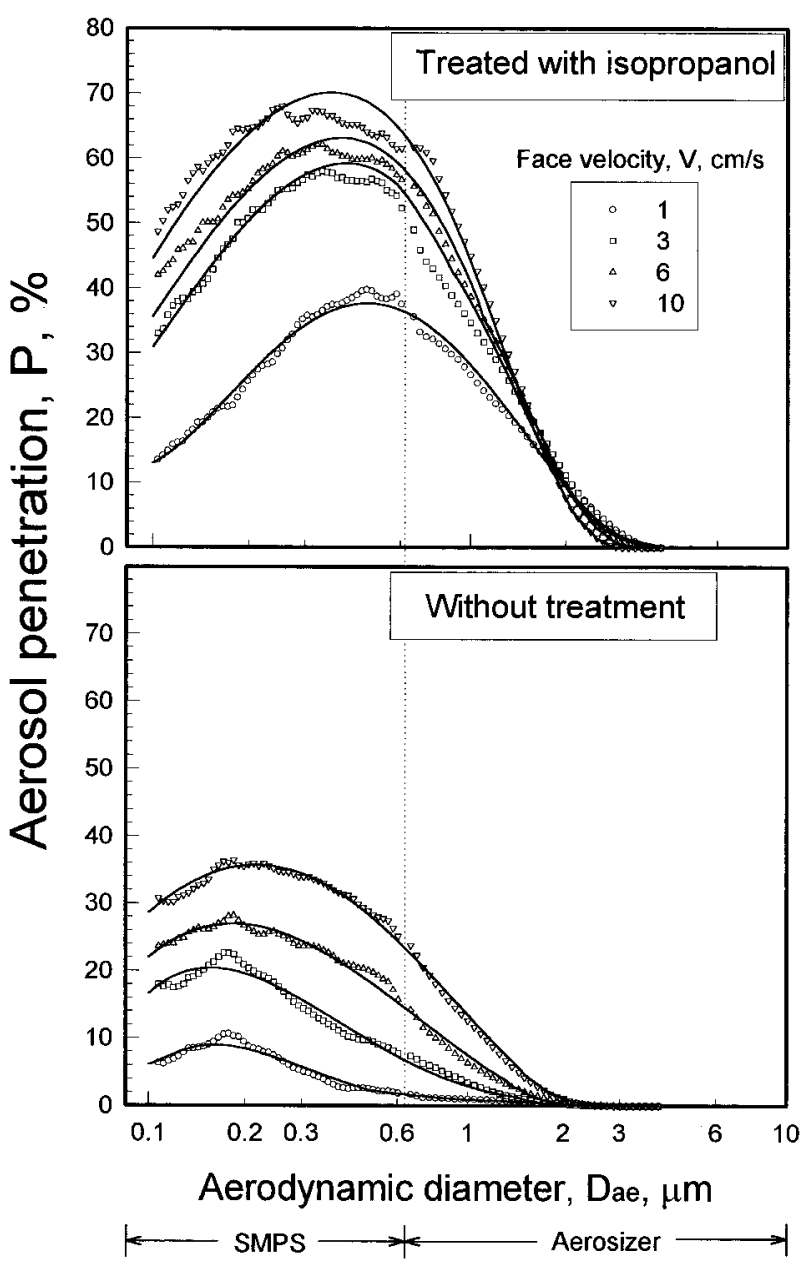

FIGURE 4. Aerosol penetration through filtering facepieces, (a) treated with isopropanol, and (b) without treatment
The penetration data above $4 \mu \mathrm{m}$ are not presented because the number counts of aerosol penetrating the filter were too low to be statistically significant. The penetrations of micrometer-sized aerosol particles through the treated filter showed a unique pattern, as can be seen in Figure 5, which is a blowup of the Aerosizer data in Figure 4. At low flow rates, there was more time for aerosol particle removal by electrostatic attraction and diffusion, and therefore less aerosol penetration by particles $1.7 \mu \mathrm{m}$ and smaller. As the particle inertia (product of mass and face velocity) increased, inertial capture became more significant. As shown in Figure 5 , for particles larger than $1.7 \mu \mathrm{m}$, removal by mechanical filtration mechanisms such as interception and inertial impaction dominated; therefore, aerosol penetration decreased as the face velocity increased. Again, this pattern did not occur with the electret filter, indicating that electrostatic attraction still prevailed in the indicated size range.

The measurement of charge density by fiber scanning on the fiber is tedious and usually incomplete, and measurement by ionizing radiation is difficult to identify with precision. Due to the level of effort and difficulty required, fiber charge density measurement was not performed in the present study. The total single fiber efficiency, $\mathrm{E}_{\Sigma, \mathrm{n}}$ was used to calculate the aerosol penetration (Equations 1 and 2). Figure 6 shows the results of the calculations applied to the electret and treated filters. The thin lines show the modeled penetration; the thick lines represent the experimental data. As shown in Figure 6, the modeled data does not match the experimental data. An inhomogeneity factor was introduced to account for the nonuniformity in fiber distribution and the variability in fiber diameter, as reported in a previous study, ${ }^{(15)}$ but this approach did not totally bridge the gap between the single fiber theory and the experiment. Hence, an equivalent fiber diameter was back-calculated to fit the modeled curves to the experimental ones. The equivalent fiber diameter was found to be about 4.6 $\mu \mathrm{m}$. The fiber charge densities held by the isopropanol-treated filter and the electret filter were calculated to be $2.1 \times 10^{-6} \mathrm{cou}^{-}$ lomb per square meter $\left(\mathrm{C} / \mathrm{m}^{2}\right)$ and $1.35 \times 10^{-5} \mathrm{C} / \mathrm{m}^{2}$, respectively. The aerosol penetration at the highest face velocity $(10 \mathrm{~cm} /$ sec) was selected for the high (also stable) penetration in the submicrometer-size range, so the estimation of the fiber charge density would be easier and more accurate.

As expected, for a fixed aerosol size the aerosol penetration decreased with increasing particle charge, as shown in Figure 7. Attempts to generate aerosol particles smaller than $1 \mu \mathrm{m}$ were without success due to the impurity problem and the lack of control over the conductivity of the solution. The upper size limit was 


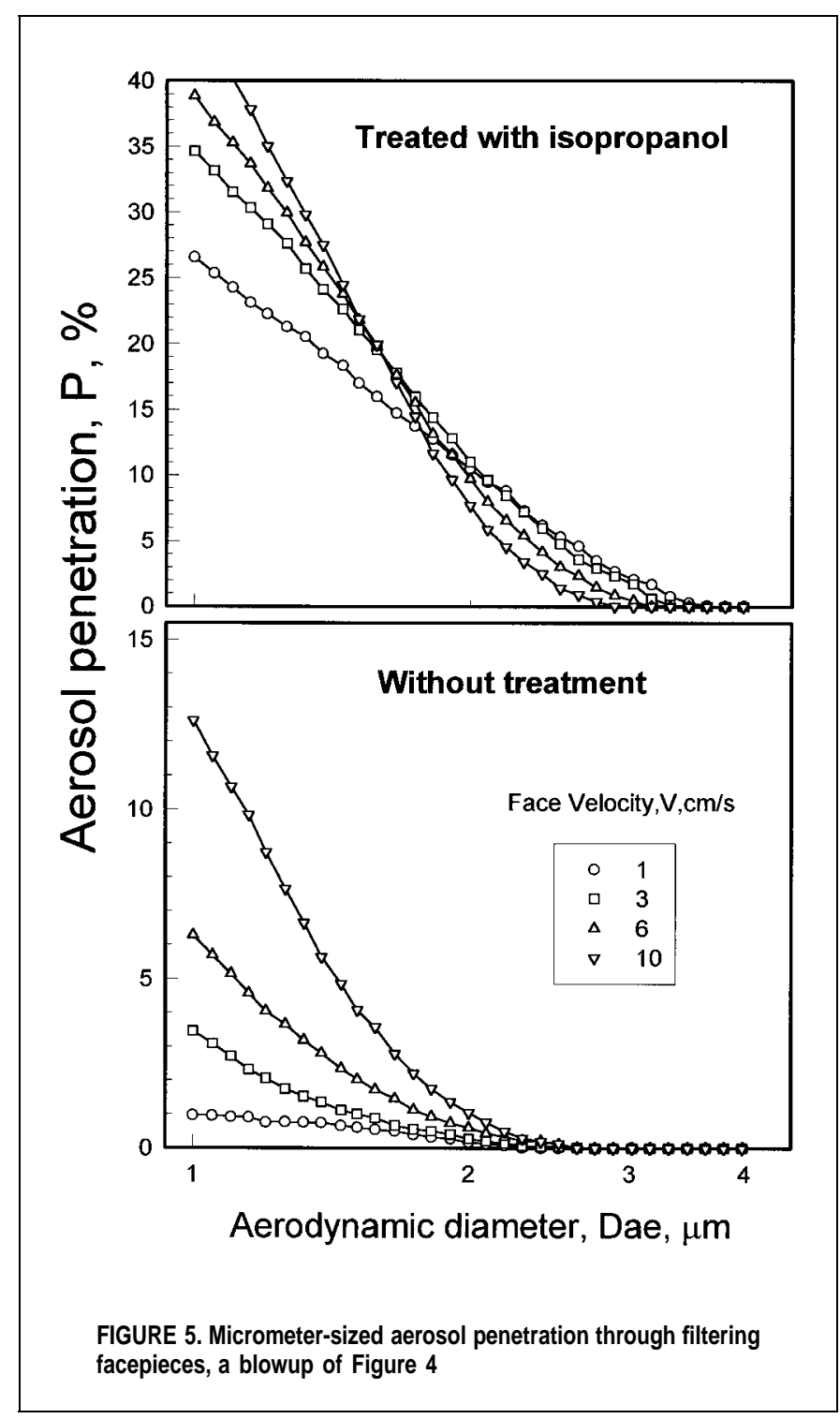

set at $2.5 \mu \mathrm{m}$ due to the low penetration of large aerosol particles. The $1-\mu \mathrm{m}$ aerosol penetrations through the isopropanol-treated filter decreased from 46 to $22 \%$ when the particle charges increased from 0 to 100 elementary charges. Consequently, the neutralization of the challenge aerosol particles is a critical and essential part of the filter testing requirements. Another unique phenomenon shown in Figure 7 is that the drop in aerosol penetration is much more drastic for smaller particles than for larger ones. Accordingly, the most penetrating size shifted to the right as the particle charge increased. The change in size of the most penetrating particle has also been mentioned in previous studies. ${ }^{(15,16)}$ This clearly demonstrates that the most penetrating particulate is in the micrometer-sized range, for particle charges larger than 400 elementary charges.

The particle charge effect, i.e., the Coulombic force and image force, was included in the single fiber theory as part of the electrostatic attraction mechanism, and the results of the calculations are expressed in Figure 8. The modeled data and the experimental data had good agreement for both the treated and electret facepieces. When the particle charge increased, the shift of the most penetrating aerosol size to the right was more noticeable with the assistance of the modeling. The penetration of charged aerosol

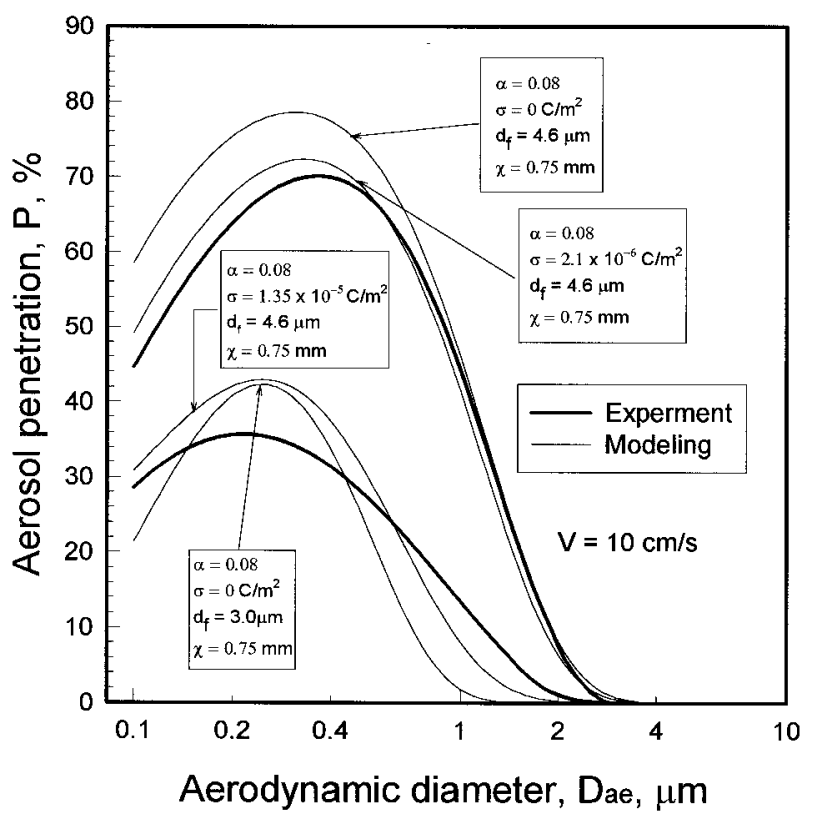

FIGURE 6. Comparison of theoretical calculations to experimental data of a filtering facepiece

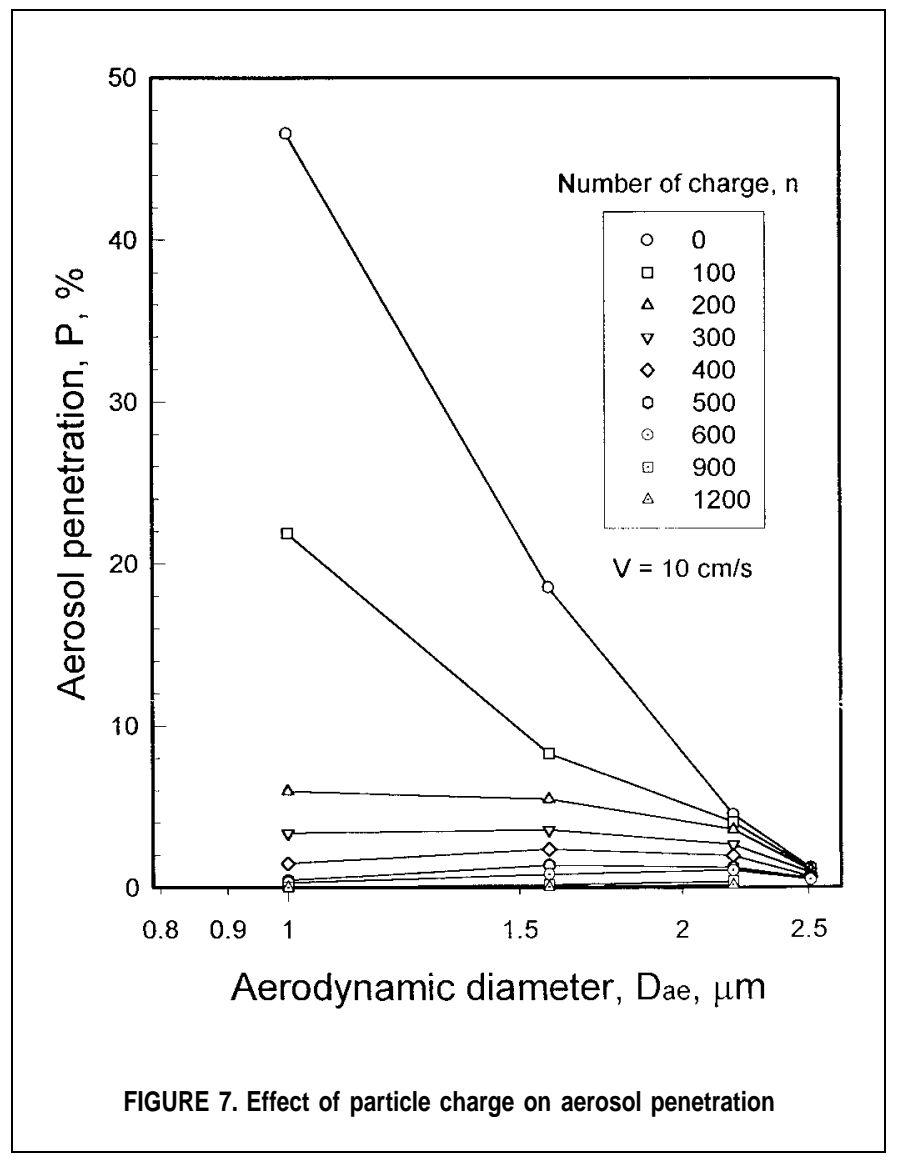




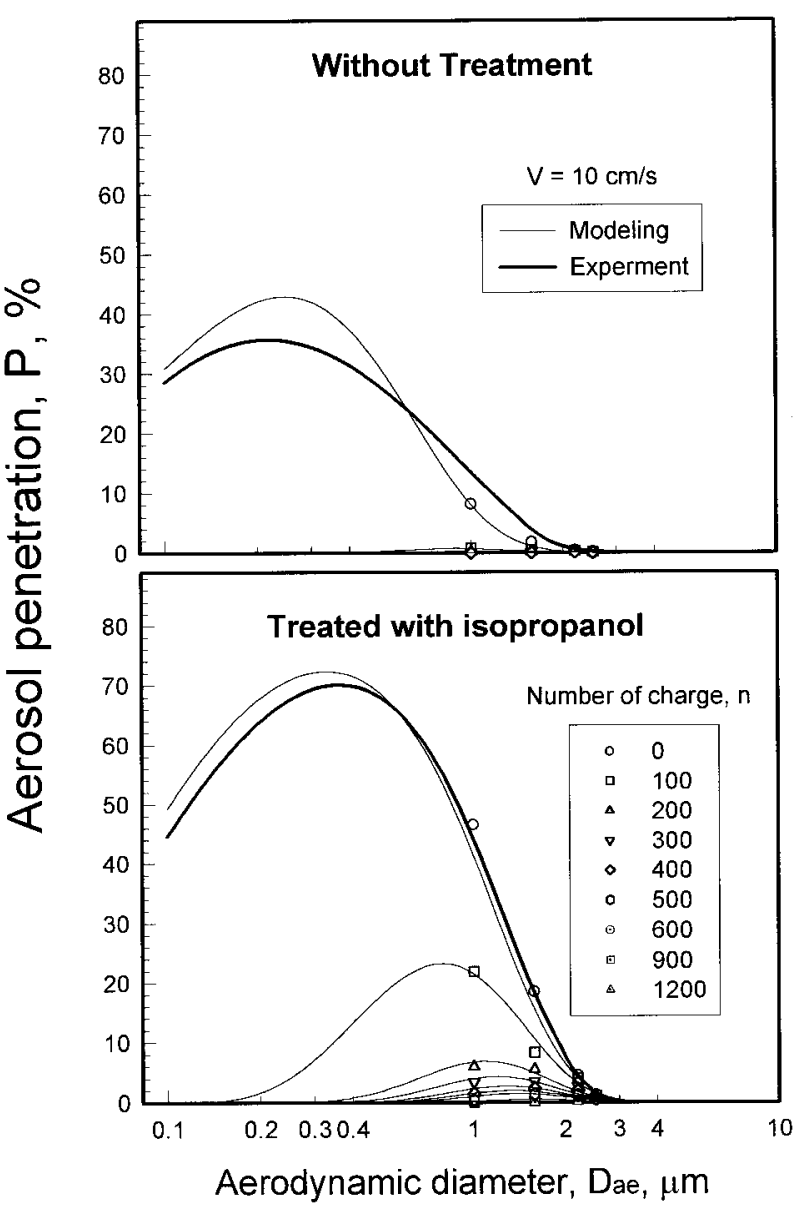

FIGURE 8. Particle size and charge dependency of penetrated aerosols for a filtering facepiece

particles through the electret was almost invisible, indicating that the coulombic force and image force were more governing than the rest of the filtration mechanisms.

Figures 7 and 8 also show that the collection efficiency due to the charges added earlier to the test aerosols was more visible than the preceding charges. For example, the aerosol penetration of $0.3-\mu \mathrm{m}$ particles through the filter without embedded charge was about $70 \%$, i.e., $30 \%$ in terms of collection efficiency, as shown in Figure 8 . The first 100 charges caused the collection efficiency to jump from 30 to $93 \%$; the subsequent 100 charges added only $7 \%$, and that led to virtually $0 \%$ aerosol penetration. To further control the aerosol charge in finer scale was too difficult and tedious, and was not performed in the present study. Yet, it is logical to infer that the first elementary charge added to the challenge aerosol is likely to add another $1 \%$ collection efficiency to the original capability due to pure mechanical force. All these points may imply that when a filter test is conducted, the shift in charge state of challenge aerosol might alter the outcome of filter testing, if the discharger or the neutralizer is not well controlled and maintained to keep the balance of the polarity, and to reduce the charge level to be at least comparable to the Boltzmann charge equilibrium.

The strong Coulombic force and image force between the charged fiber and particle could also be demonstrated by showing

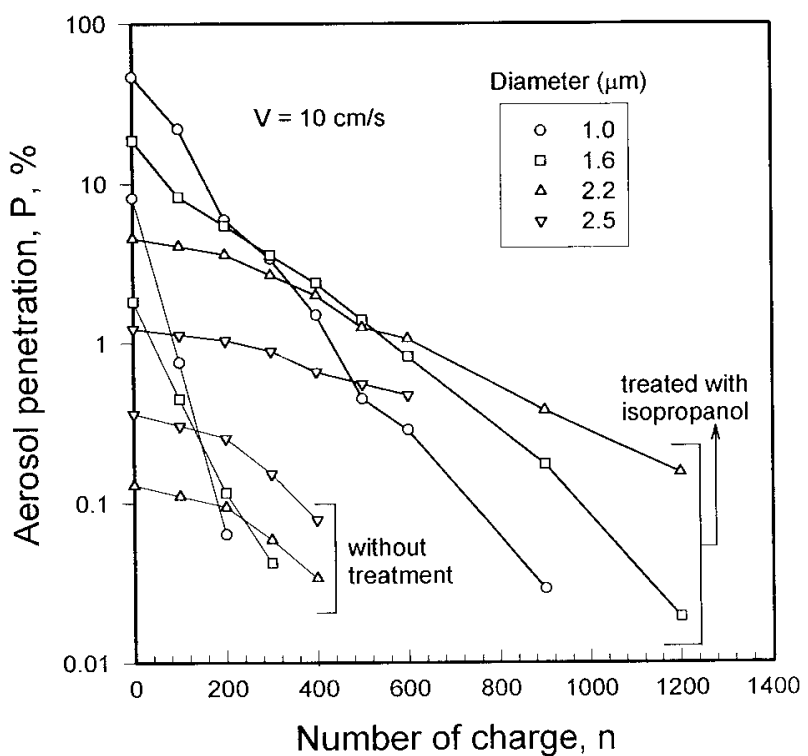

FIGURE 9. Effect of particle size on aerosol penetration through filtering facepieces

the aerosol penetration as a function of particle charge, as shown in Figure 9. The aerosol penetrations through the treated filter were higher than through the electret filter. The drop in penetration of smaller particles (through the isopropanol treated filter) such as $1-\mu \mathrm{m}$ was much more drastic than that of the larger particles, with the same result for the electret filter. The shift in the most penetrating aerosol size was quite radical for the first 200 elementary charges, as shown in Figure 10. However, as the particle charge kept increasing, the increase in the most penetrating aerosol size was not as clear, indicating that impaction and interception became more dominant as the aerosol size increased.

\section{CONCLUSIONS AND RECOMMENDATIONS}

A filter testing system has been developed and established to study the effects of particle charge on filter performance. The vibrating orifice monodisperse aerosol generator was able to generate monodisperse aerosols with uniform charge for particle sizes larger than $1 \mu \mathrm{m}$. Methods need to be developed to generate submicrometer-sized aerosols with controlled charge.

The equivalent fiber diameter of the tested facepiece was calculated to be $4.6 \mu \mathrm{m}$, and the fiber charge density was estimated to be about $1.35 \times 10^{-5} \mathrm{C} / \mathrm{m}^{2}$. The aerosol penetration decreased with increasing particle charge. The drop in aerosol penetration was most significant for the first 200 elementary charges, and the most penetrating aerosol size became larger as the particle charge increased. The electric charge on aerosol particles makes a significant difference to the filtration efficiency performance of both electret and mechanical filters. This is the result of a combination of the Coulombic force, the dielectrophoretic force, and the image force, which are considered dominant filtration mechanisms for submicrometer-sized aerosols.

The first elementary charges added to the particles are more influential in improving the filter collection efficiency than the charges added later. Although the charge carried by one particle 


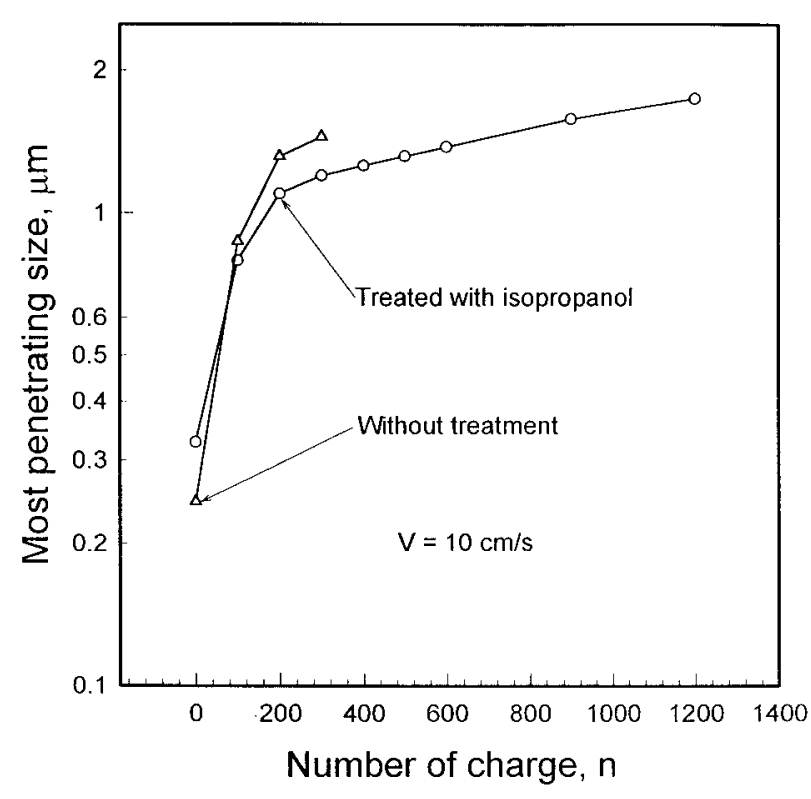

FIGURE 10. Effect of particle charge on the most penetrating size

rarely exceeded 50 elementary charges and posed no problem to aerosol sampling, this amount of charge on the challenge particle might make a difference in the outcome of the filter test. Therefore, it is critical to assure that the dischargers or neutralizers are maintained and operated properly. The face velocity was $10 \mathrm{~cm} /$ sec, chosen out of convenience for this study, although in the workplace a $10 \mathrm{~cm} / \mathrm{sec}$ face velocity represents a heavy work rate situation. That implies the respirator will be more protective if the work load is lower and the aerosol charge state is not neutral.

\section{REFERENCES}

1. Moyer, E.S., and G.A. Stevens: "Worst case" aerosol testing parameters: II. Efficiency dependence of commercial respirator filters on humidity pretreatment. Am. Ind. Hyg. Assoc. J. 50:265-270 (1989).

2. Moyer, E.S., and G.A. Stevens: "Worst case" aerosol testing parameters: III. Initial penetration of charged and neutralized lead fume and silica dust aerosols through clean, unloaded respirator filters. Am. Ind. Hyg. Assoc. J. 50:271-274 (1989).

3. Chen, C.C., M. Lehtimaki, and K. Willeke: Aerosol penetration through filtering facepieces and cartridges. Am. Ind. Hyg. Assoc. J. 53: 566-574 (1992).

4. Chen, C.C., M. Lehtimaki, and K. Willeke: Loading and filtration characteristics of filtering facepieces. Am. Ind. Hyg. Assoc. J. 54:51$60(1993)$

5. Johnston, A.M., J.H. Vincent, and A.D. Jones: Measurement of electrical charge of workplace aerosols. Ann. Occup. Hyg. J. 29:271284 (1985).

6. John, W., and J.H. Vincent: Static electrification of workplace aerosols: a perspective. Ann. Occup. Hyg. J. 29:285-288 (1985).

7. "Respiratory Protective Devices." Code of Federal Regulations Title 42, Part 84, 1995.

8. Reischl, G., W. John, and W. Devor: Uniform electrical charging of monodisperse aerosols. J. Aerosol Sci. 8:55-65 (1977).

9. Hinds, W.C.: Aerosol Technology. New York: John Wiley \& Sons, 1982. pp. 164-186

10. Tennal, K.B., M.K. Mazumder, A. Siag, and R.N. Reddy: Effect of loading with an oil aerosol on the collection efficiency of an electret filter. Particulate Sci. Technol. 9:19-29 (1991).

11. Lee, K.W., and B.Y.H. Liu: Theoretical study of aerosol filtration by fibrous filter. Aerosol Sci. Technol. 1:147-161 (1982).

12. Lathrache, R., and H.J. Fissan: Enhancement of particle deposition in filters due to electrostatic effects. Proc. Filtration Soc. 1987. pp. $418-422$.

13. Brown, R.C.: Behavior of electrostatic filters made of fibers or sheets arranged parallel to the air flow. J. Aerosol Sci. 13: 249-257 (1982).

14. Pich, J.: Theory of air filtration by fibrous and membrane filters. In Aerosol Science, C.N. Davies (ed.). London: Academic Press, 1966.

15. Liu, B.Y.H., and K.L. Rubow: Air filtration by fibrous media. In Fluid Filtration: Gas, vol. 1, R.R. Raber (ed.), (ASTM special tech. pub. 975). Philadelphia, PA: ASTM, 1986. pp. 1-12.

16. Zhang, Z., and B.Y.H. Liu: Experimental study of aerosol filtration in the transition flow region. Aerosol Sci. Technol. 16:227-235 (1992). 